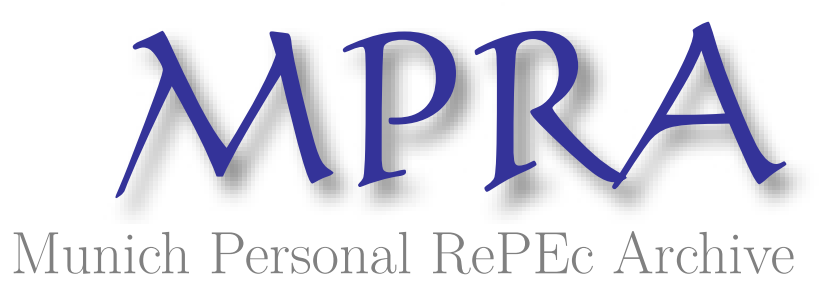

\title{
International framework for liquidity risk measurement, standards and monitoring: corporate governance and internal controls
}

\author{
Ojo, Marianne
}

Center for European Law and Politics, University of Bremen, Oxford Brookes University

April 2010

Online at https://mpra.ub.uni-muenchen.de/21847/

MPRA Paper No. 21847, posted 12 Apr 2010 02:04 UTC 


\begin{abstract}
This paper is structured in accordance with identified components which are considered to be essential to the successful implementation of the (two fold) topics of discussion of this paper, namely, monitoring and liquidity risk measurements. The importance of successfully communicating results obtained from monitoring and measuring such risks, and the role of corporate governance in ensuring such effective communication, constitutes a recurring theme throughout this paper. The identified components are as follows: i) Corporate governance (ii) Internal controls (iii) Disclosure (iv) Management of risk (v) Substance over form (vi) Transparency

As well as highlighting the interdependence of these components, the paper also aims to accentuate the importance of individual components. Whilst no hierarchy of importance is assigned to these components, corporate governance and internal controls are two components which are analysed in greater depth (than other components). Furthermore, corporate governance could be accorded a status of greater importance than internal controls having regard to the fact that whilst internal controls relate to a very vital control aspect of an organisation, corporate governance relates to all processes - be it decision making, control, production, performance, within a company/bank.
\end{abstract}

The paper will also attempt to demonstrate that it is possible to implement a system of regulation which combines increased formalised procedures and/or detailed rules - whilst giving due consideration to the substance of transactions.

Key words: corporate governance; internal controls; monitoring; liquidity; regulation 


\title{
INTERNATIONAL FRAMEWORK FOR LIQUIDITY RISK MEASUREMENT, STANDARDS AND MONITORING: CORPORATE GOVERNANCE AND INTERNAL CONTROLS
}

\author{
Marianne Ojo ${ }^{l}$
}

A. Introduction

The Basel Committee's recent focus is reflected through its goals of not only intensifying the "resilience of internationally active banks to liquidity stresses", but also intensifying international harmonisation of liquidity risk supervision. These efforts are aimed at consolidating recent work which culminated in the issue of the Principles for Sound Liquidity Risk Management and Supervision. $^{2}$

As part of measures aimed at facilitating "further consolidation and promotion of consistency in international liquidity risk supervision", and in response to the "inaccurate and ineffective management of liquidity risk" - such ineffective management being a prominent feature of the financial crisis, the Basel Committee has developed a minimum set of monitoring tools to be used in the "ongoing monitoring of the liquidity risk exposures of cross border institutions and in communicating these exposures amongst home and host supervisors."

This paper is structured in accordance with identified components which are considered to be essential to the successful implementation of the (two fold) topics of discussion of this paper, namely, monitoring and liquidity risk measurements. The importance of successfully communicating results obtained from monitoring and measuring such risks, and the role of corporate governance in ensuring such effective communication, constitutes a recurring theme throughout this paper. The identified components are as follows: i) Corporate governance (ii) Internal controls (iii) Disclosure (iv) Management of risk (v) Substance over form (vi) Transparency

Disclosure and transparency embody the same goals, whilst the effective management and measurement of risks, and liquidity risks in particular, are aims which the internal control function and management should strive to achieve. The theme "substance over form" draws attention to creative accounting practices and the need for greater emphasis on principles based regulation. Creative accounting and "window dressing" of figures in the financial statements are ever recurring issues arising from corporate collapses - as also recently highlighted by the recent crises which involved Lehman Brothers.

Whilst the danger of formalism lies in the exercise of "creative compliance", ${ }^{4}$ inherent problems of anti formalism are considered to include: ${ }^{5}$

- The fact that citizens have the right to know exactly what is prohibited in advance of behaviour rather than in retrospect

\footnotetext{
Researcher, Center for European Law and Politics (ZERP), University of Bremen and Teaching Associate, Oxford Brookes University, Oxford.

2 See Consultative Document „International Framework for Liquidity Risk Measurement, Standards and Monitoring at page 2

ibid

4 Creative compliance being the use of rules to escape control without actually violating those rules

5 V Beattie, S Fearnley and R Brandt Behind Closed Doors: What Company Audit is Really About (ICAEW) 2001 at page 11
} 
- That broad rules are imprecise and over inclusive

- That anti formalism could result in ineffective control - where it is impossible to implement

Principles based regulation (PBR) is more advantageous than a rules based approach - owing to the fact that off balance ${ }^{6}$ sheet debt could result from the direct application of rules - without being able to consider the substance of the transaction and because the implemented standards do not allow such consideration. As its secondary argument ${ }^{7}$, this paper will seek to demonstrate that detailed rules could still operate within a system of principles based regulation - whilst enabling a consideration of the substance of the transactions which are involved.

Regulatory standards implemented by the Basel Committee in its recent document ${ }^{8}$ provide for "jurisdiction-specific conditions" - for example, the percentage of potential run-off of retail deposits which is partially dependent on the structure of a jurisdiction's deposit insurance scheme." 9 Furthermore, the Committee highlights that "in these cases, the parameters should be transparent and clearly outlined in the regulations of each jurisdiction." ${ }^{10}$ It also adds that this would provide clarity both within the jurisdiction as well as across borders concerning the precise parameters that the banks are capturing in these metrics, and that there was need for public disclosures in respect of regulatory standards. ${ }^{11}$

Good corporate governance would "provide proper incentives for the board and management to pursue objectives that are in the interests of the company and its shareholders." 12 The dual faceted aspects of corporate governance relate not only to the accountability of management to shareholders, but also to the supervision and monitoring of management performance. Good corporate governance should facilitate effective monitoring, effective management of internal controls and risks, effective disclosure and transparency.

In considering the topics of discussion, namely, liquidity risk measurements and monitoring, this paper will commence with a section dedicated to liquidity risk (and risk measurements), along with developments which have triggered the need for particular monitoring tools - both in response to global developments and with particular reference to the increasing prominence of liquidity risks.

The ever growing prominence and importance of liquidity in prudential supervision constitutes a vital reason which justifies the need for a prudential supervisory framework which does not merely (and excessively) rely on capital adequacy requirements within such a framework.

Some arguments which revolve around the inadequacies of capital adequacy standards include: ${ }^{13}$ the fact that:

- "Capital ratios may be of limited value as indicators of actual risk since reported capital positions do not reflect the real causes of most bank failures ( the real causes of bank failures being fraud or fast depletion of the banks' resources)

${ }^{6}$ Off balance sheet items are obligations which are contingent liabilities of a company/bank - and which as a result, do not appear on its balance sheet. Formal distinction between on and off balance sheet items, even though sometimes detailed, depend to an extent on the degree of judgement which is exercised by management.

7 The primary theme being the importance of successfully communicating results obtained from monitoring and measuring such risks, and the role of corporate governance in ensuring such effective communication.

8 See Consultative Document, „International Framework for Liquidity Risk Measurement, Standards and Monitoring" at page 2

9 ibid

10 ibid

11 ibid

12 See Basel Committee on Banking Supervision "Enhancing Corporate Governance for Banking Organisations" February 2006 at page 4

13 C Hadjiemmanuil, Banking Regulation and the Bank of England Lloyds of London Press 1995 at page 210 
- The international minimum ration of $8 \%$ lacks any theoretical justification

- Risk related measurement of bank assets is not only deeply flawed, but also triggers substantial distortions in the relative demand for bank assets.

- Since banks are in direct competition with investment firms, so far as securities activities are concerned, the imposition of capital burdens on banks erodes their ability to compete."

Paragraph 56 of the Basel Committee on Banking Supervision's Principles for Sound Liquidity Risk Management and Supervision states that

"A bank should have a reliable management information system designed to provide the board of directors, senior management and other appropriate personnel with timely and forward-looking information on the liquidity position of the bank. The management information system should have the ability to calculate liquidity positions in all of the currencies in which the bank conducts business - both on a subsidiary/branch basis in all jurisdictions in which the bank is active and on an aggregate group basis. It should capture all sources of liquidity risk, including contingent risks and the related triggers and those arising from new activities, and have the ability to deliver more granular and time sensitive information during stress events. To effectively manage and monitor its net funding requirements, a bank should have the ability to calculate liquidity positions on an intraday basis, on a day-to-day basis for the shorter time horizons, and over a series of more distant time periods thereafter. The management information system should be used in day-to-day liquidity risk management to monitor compliance with the bank's established policies, procedures and limits." 14

\section{B. Liquidity Risks}

In February 2008, the Basel Committee on Banking Supervision published a paper titled "Liquidity Risk Management and Supervisory Challenges", a paper which highlighted the fact that many banks had ignored the application of a number of basic principles of liquidity risk management during periods of abundant liquidity. ${ }^{15}$ An extensive review of its 2000 "Sound Practices for Managing Liquidity in Banking Organisations" was also carried out by the Basel Committee as a means of addressing matters and issues arising from the financial markets and lessons from the Financial Crises. ${ }^{16}$ In order to consolidate on the Basel Committee for Banking Supervision's Principles for Sound Liquidity Risk Management and Supervision of September 2008, which should lead to improved management and supervision of liquidity risks of individual banks, supervisory bodies will be required " to develop tools and policies to address the pro cyclical behaviour of liquidity at the aggregate level. ${ }^{17}$

\footnotetext{
${ }^{14}$ Basel Committee on Banking Supervision,Principles for Sound Liquidity Risk Management and Supervision Sept 2008 at page $17<\mathrm{http} / /$ www.bis.org/publ/bcbs144.htm $>$ Furthermore, paragraph 57 highlights the importance of a consensus between senior management in relation to a set of reporting criteria aimed at facilitating liquidity risk monitoring. Such reporting criteria should specify “"'the scope, manner and frequency of reporting for various recipients (such as the board, senior management, asset - liability committee) and the parties responsible for preparing the reports." "Reporting of risk measures should be done on a frequent basis (eg daily reporting for those responsible for managing liquidity risk, and at each board meeting during normal times, with reporting increasing in times of stress) and should compare current liquidity exposures to established limits to identify any emerging pressures and limit breaches. Breaches in liquidity risk limits should be reported and thresholds and reporting guidelines should be specified for escalation to higher levels of management, the board and supervisory authorities."

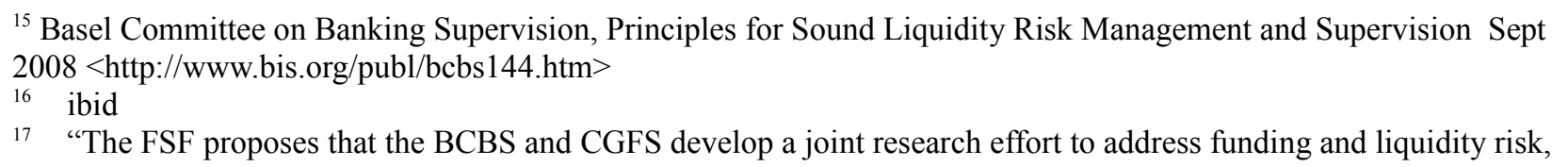


The Principles for Sound Liquidity Risk Management and Supervision of September 2008 are aimed at providing "consistent supervisory expectations" on principal elements such as "board and senior management oversight; the establishment of policies and risk tolerance; the use of liquidity risk management tools such as comprehensive cash flow forecasting, limits and liquidity scenario stress testing; and the maintenance of a sufficient cushion of high quality liquid assets to address contingent liquidity needs." 18

The three aspects to pro cyclicality ${ }^{19}$ - as highlighted in the Impact Assessment Document amending the Capital Requirements Directive, have the potential to trigger a chain reaction. Starting with remuneration schemes, the impact of these on management incentives, could have a positive or negative effect on bank regulations (such as Basel II or the CRD). Such regulations could then mitigate or exacerbate pro cyclical effects - depending on the effectiveness of capital adequacy rules. A positive effect of such rules would reduce the tendency of banks to cut back on lending during economic "busts" whilst incentives to retain liquidity would be increased - hence reducing the likelihood of the occurrence of maturity mismatches.

The link between liquidity and systemic risks as illustrated in the ECB's Financial Stability Review, is attributed to the "destruction of specific knowledge ${ }^{20}$ which banks have about their borrowers and the reduction of the common pool of liquidity." 21 The importance of the link between liquidity risks and systemic risks within the banking sector is highlighted by the consequences attributed to the reluctance of banks to retain liquidity - given the cost of holding liquidity. ${ }^{22}$ The consequential shortfalls of liquidity as reflected by on and off balance sheet maturity mismatches accentuates the importance of the role assumed by central banks in the funding of bank balance sheets. ${ }^{23}$

The link between liquidity and systemic risks is also accentuated under paragraph 77 of the BCBS Principles for Sound Liquidity Risk Management and Supervision of September 2008. Principle 8 states that:

"A bank should actively manage its intraday liquidity positions and risks to meet payment and settlement obligations on a timely basis under both normal and stressed conditions and thus contribute to the smooth functioning of payment and settlement systems."

Paragraph $77^{24}$ elaborates on this by highlighting the reasons why "intraday liquidity management" constitutes an important component of a bank's "broader liquidity management strategy." It goes on

starting in 2009. A key component of this research agenda is to define robust measures of funding and liquidity risk, which could assist assessments of liquidity risk by the private sector. Stress tests to gauge the probability and magnitude of a liquidity crisis in different market environments will be considered in this light." For further information on this, see Report of the Financial Stability Forum on Addressing Pro cyclicality in the Financial System: Measuring and Funding Liquidity Risk" http://www.financialstabilityboard.org/publications/r 0904a.pdf at page 24

18 See Basel Committee on Banking Supervision, Consultative Document "International Framework for Liquidity Risk, Measurement Standards and Monitoring” Bank for International Settlements Publications at page 1

19 Namely: systemic aspects, bank regulations and remuneration policies

${ }^{20}$ Since specific knowledge which banks possess about their borrowers is considered to be a factor which determines the illiquidity of bank loans; see "The Concept of Systemic Risk" ECB Financial Stability Review December 2009 at page $137<$ http://www.ecb.int/pub/fsr/shared/pdf/ivbfinancialstabilityreview200912en.pdf?05d3164914c6a14bb13522 $2 \mathrm{~b} 5 \mathrm{c} 3894 \mathrm{fa}>$

${ }^{21}$ ibid; According to the Review, the reduction in the common pool of liquidity also has the potential to trigger the failure of banks and could consequently lead to a devaluation of illiquid bank assets and further aggravation of problems within the banking sector.

${ }^{22}$ Report of the Financial Stability Forum on "Addressing Pro cyclicality in the Financial System: Measuring and Funding

Liquidity Risk" http://www.financialstabilityboard.org/publications/r_0904a.pdf at page 24

23 ibid

${ }^{24}$ Principles for Sound Liquidity Risk Management and Supervision Sept 2008 at pages 20 and 21 
to state that a bank's failure to manage intraday liquidity effectively could result in its inability to meet payment obligations as they fall due, - hence generating consequences, not only for its own liquidity position, but also that of other parties. It illustrates how this could occur in two ways, namely:

- "The fact that that counter parties may view the failure to settle payments when expected, as a sign of financial weakness - which in turn could result not only in payments to the bank being delayed or withheld, but also in further aggravation of liquidity pressures.

- It also could leave counterparties unexpectedly short of funds, impair those counterparties' ability to meet payment obligations, and disrupt the smooth functioning of payment and settlement systems. Given the interdependencies that exist among systems, a bank's failure to meet certain critical payments could lead to liquidity dislocations that cascade quickly across many systems and institutions. If risk controls are overwhelmed, these dislocations could alter many banks' intraday or overnight funding needs, including their demands for central bank credit, and potentially affect conditions in money markets. The delay of other less critical payments also might cause other institutions to postpone their own payments, cause many banks to face increased uncertainty about their overnight funding needs and potentially increase the impact of any operational outages."

Liquidity is considered to be "highly procyclical, growing in good times and drying up in times of stress." ${ }^{25}$ During the build up to the present crisis, banks and other financial institutions had an incentive to minimise the cost of holding liquidity. ${ }^{26}$ Given the fact that liquidity could also be pro cyclical and given its role in the recent crisis, perhaps four dimensions to pro cyclicality should have been introduced in the Impact Assessment Document ${ }^{27}$ amending the Capital Requirements Directive - incorporating liquidity as a fourth heading.

The growing importance of formalisation within the bank regulatory framework is also attributed to the gaps which exist within a discretionary based system of bank supervision - as was revealed in the aftermath of Baring Plc's collapse. The recent crisis has also highlighted the need for formal risk assessment models - as demonstrated by the demise of Lehman Brothers where the failures of auditors to detect balance sheet irregularities (owing to creative accounting practices) was brought to light.

The formal framework for the measurement of capital adequacy at European Community level, as exemplified by the International Convergence of Capital Measurements and Capital Standards(Revised Framework), namely Basel 2, is to be commended, not only because of "the need for a consistent framework for the reporting and comparative analysis of bank capital positions, the demand of regulated institutions for transparency and equality in the application of regulatory standards", but also because of "the exigencies of the international convergence process - which requires the transparent and uniform implementation of harmonised rules by the regulators of every country." 28

\footnotetext{
${ }^{25}$ See Report of the Financial Stability Forum on Addressing Pro cyclicality in the Financial System "Measuring and Funding Liquidity Risk" at page 24

${ }^{27}$ See Accompanying Document to the Proposal for a Directive of the European Parliament and of the Council amending Capital Requirements Directive on trading book, securitisation issues and remuneration policies. $<$ http://ec.europa.eu/internal_market/bank/docs/regcapital/com2009/impact_assesment_en.pdf>See page 44-46

28 See C Hadjiemmanuil, Banking Regulation and the Bank of England Lloyds of London Press 1995 at pages 208 209
} 
As part of measures aimed at consolidating and "promoting consistency in international liquidity risk supervision", and in response to the "inaccurate and ineffective management of liquidity risk" as was prominently highlighted during the recent financial crisis, the Basel Committee has developed a "minimum set of monitoring tools to be used in the ongoing monitoring of the liquidity risk exposures of cross border institutions and in communicating these exposures amongst home and host supervisors." ${ }^{29}$

The Liquidity Coverage Ratio ${ }^{30}$ and the Net Stable Funding Ratio ${ }^{31}$ are two regulatory standards for liquidity risk which serve the purpose of attaining the objectives of "promoting short-term resiliency of the liquidity risk profile of institutions" (by ensuring that they have adequate high quality liquid resources to survive during periods of extreme stress which last for about one month) and "promoting resiliency over longer-term periods" ( through the creation of additional incentives for banks to fund their activities with more stable sources of funding on an ongoing basis). ${ }^{32}$

In addition to the above-mentioned standards, the Basel Committee recommends that supervisors also implement designated monitoring tools on a consistent basis. Such monitoring tools, along with the standards, are intended to provide supervisors with information which should aid their assessment of liquidity risks attributed to a particular bank. ${ }^{33}$ These monitoring tools include: Contractual Maturity Mismatch, Concentration of Funding, Available Unencumbered Assets and market - related monitoring tools. ${ }^{34}$

\section{Disclosure}

As well as the need for greater focus on liquidity risk, there is also the need for greater reliance on disclosure requirements. This will be facilitated through an effective monitoring process whereby identified risks are effectively communicated across all levels of management.

Enhanced transparency does not only have the potential to "improve an understanding of the mechanism at play in structured finance", but also facilitate the identification of risks and ensure that risks are well controlled. ${ }^{35}$ Risky loans which were "repackaged and sold to institutional investors" - some of whom did not fully comprehend the implications of the transactions they were engaged in (or about to be engaged in), and the inherent risks associated with those transactions, are considered to be contributory factors to the 2007/09 Financial Crisis. ${ }^{36}$

Regulators will be able to gain greater access to vital information which is required for effective performance of their functions where duties are imposed on third parties, such as external auditors, in relation to the disclosure of information which is necessary and required for the efficient performance of the regulators' activities - as opposed to a right to report.

29 See Bank for International Settlements, Consultative Document "International Framework for Liquidity Risk, Measurement Standards and Monitoring" at page 2

30 This ratio, ,identifies the amount of unencumbered, high quality liquid assets an institution holds that can be used to offset the net cash outflows it would encounter under an acute short-term stress scenario by supervisors." ibid at page 3

31 This ratio measures "the amount of longer-term, stable sources of funding utilised by an institution relative to the liquidity profiles of the assets being funded and the potential for contingent calls on funding liquidity arising from off-balance sheet commitments and obligations." ibid

32 ibid

33 ibid at page 25

34 ibid

35 See speech by C McCreevy European Commissioner for Internal Market an Services at the European Parliament 11 Sept 2007 http://europa.eu/rapid/pressReleasesAction.do? reference $=$ SPEECH/07/520\&format $=$ HTML\&aged=1\&language $=E N \&$ guiLanguage $=e n$ 
The relationship between supervisory authorities and the external auditors of a credit institution and the duties of these auditors was identified as an important lesson from the BCCI case.$^{37}$ Because of auditors' access to financial undertakings' accounts and other essential documents and information, they assume a vital position in the overall supervisory process. An analysis of BCCI revealed that measures, additional to those already existing, needed to be taken to eliminate the opaqueness of financial structures and strengthen cooperation between all bodies or persons involved in the supervision of such complex financial structures. ${ }^{38}$

As a result, the Basel Committee for Banking Supervision issued "minimum standards" which lay down rules for effective consolidated supervision and cooperation between supervisory authorities. This was not only aimed at strengthening international co operation between prudential supervisors, but also to improve transparency of financial, and in particular, group structures.

\section{The Importance of Effective Management of Internal Controls}

"Banks identified as having control problems have been characterised by organisational structures in which responsibilities were not clearly defined: hence (1) No senior management monitored the performance of activities (carried out within the organisation) closely to observe unusual activities 2) No senior management had a comprehensive understanding of the activities and how profits were being generated." ${ }^{39}$

The collapse of Barings in1995 which was attributed not only to lack of quality and employee deception, also brought the issue of internal controls and management systems to the fore. ${ }^{40}$ Barings collapse illustrated weaknesses in the bank regulator's supervisory regime - which included flaws within its evaluation of internal controls at banks, flaws inherent in the internal communication within levels of management of the bank regulator, and the weaknesses in the way the bank regulator's existing rules were applied. ${ }^{41}$

The Basel Committee categorised into five groups, types of control breakdowns which are characteristic of ailing banks and these are as follows: ${ }^{42}$

- Lack of adequate management oversight and accountability, and failure to develop a strong control culture within the bank ${ }^{43}$

37 JF Mogg, ,The Bank of England and the Development of Internal Control Systems' in R Kinsella (ed) Internal Controls in Banking (Oak Tree Press Dublin 1995) at page 31

38 ibid at page 28

39 See "Framework for Internal Control Systems in Banking Organisations", Basel Committee for Banking Supervision 1998 at page 27

40 Whilst it is contended by some that the problems attributed to Barings focussed round the lack of controls, the system of internal controls which operated were also considered by the regulator at the time (the Bank of England) to be informal but effective. See Barings Bank and International Regulation Volume 1 (12 December 1006) at page xiii

41 See Treasury Committee, Barings Bank and International Regulation Report No 11996 page xv

42 See Framework for Internal Control Systems in Banking Organisations, Basel Committee for Banking Supervision 1998 at pages 6 and 7

43 In order to evaluate the quality of internal controls, supervisors could adopt a number of approaches which include i) the evaluation of the work of the internal audit department of the bank (though review of its working papers including the methodology implemented in identifying, measuring, monitoring and controlling risks). ii) If supervisors are satisfied with the quality of the internal audit department's work, they could use the reports of internal auditors as a primary mechanism for the identification of control problems in the bank (or for identifying areas of potential risk - areas which have not been recently reviewed by the auditors). iii)Further some supervisors may use a self-assessment process in which management reviews the internal controls on a business by business basis whilst iv)other supervisors may require periodic external audits of key areas (given that supervisor defines the 
- Inadequate recognition and assessment of the risk of certain banking activities, whether on or off balance sheet

- The absence or failure of key control structures and activities such as segregation of duties, approvals, verifications, reconciliations and reviews of operating performance

- Inadequate communication of information between levels of management within the bank particularly the communication of information to higher ranked officials (senior management)

- Inadequate or ineffective audit programmes and monitoring activities

\section{E. The Contribution of Corporate Governance to an Effective System of Internal Controls}

Various corporate collapses have resulted in changes to financial reporting, corporate governance and audit. ${ }^{44}$ The emphasis on internal controls and risk management emerged from realisation that due to change in the business environment, even effective safeguards may be insufficient to eliminate all possibilities of failure. ${ }^{45}$

Keasy and Wright define corporate governance as the "examination of the structures and processes associated with production, decision making, control and so on within an organisation." 46 The two aspects of governance are considered to be i) Supervision and monitoring of management performance (the enterprise aspect) and ii) ensuring accountability of management to shareholders and other stakeholders (the accountability aspect). ${ }^{47}$

The feedback effects of corporate governance into the liquidity and systemic risk mechanisms are illustrated thus:

"Poor corporate governance may contribute to bank failures, which could pose significant public costs and consequences due to their potential impact on any applicable deposit insurance systems and the possibility of broader macro economic implications, such as contagion risk and impact on payments systems. Furthermore, poor corporate governance could result in markets losing confidence in the ability of a bank to properly manage its assets and liabilities, including deposits, which could in turn, trigger a bank run or liquidity crisis. $" 48$

As well as a robust system of internal controls (which incorporates internal and external audit functions), the implementation of i) corporate values, codes of conduct, standards of appropriate behaviour and the system used in ensuring compliance with these, ii) a clear allocation of responsibilities and decision making authorities, iii) the establishment of a system which would guarantee efficient interaction and collaboration between the board of directors, senior management and auditors, and iv) special monitoring of risk exposures where conflicts of interest are likely to be high, are considered to be crucial to ensuring that sound corporate governance operates within an

scope). Supervisors may ultimately combine one or more of the techniques highlighted under (i) - (iv) with own on site reviews or examinations of internal controls. See ibid at pages 22 and 23

44 House of Commons Select Committee on Treasury, Minutes of Evidence submitted by the Institute of Chartered Accountants in England and Wales as part of its inquiry into the arrangements for financial regulation of public limited companies at page 17

45 ibid

46 See K Keasy and M Wright, 'Issues in Corporate Accountability and Governance: An Editorial' Accounting and Business Research, 23 (91A) at page 291. OECD principles define corporate governance as involving "a set of relationships between a company's management, its board, its shareholders, and other stakeholders."

47 V Beattie, S Fearnley and R Brandt Behind Closed Doors: What Company Audit is Really About (ICAEW) 2001 at page 26

48 See Basel Committee on Banking Supervision "Enhancing Corporate Governance for Banking Organisations" February 2006 at page 4 
organisation. $^{49}$

Furthermore, sound corporate governance practices are considered to require " appropriate and effective legal, regulatory and institutional foundations." ${ }^{50}$ Even though factors such as the system of business laws and accounting standards which prevail in respective jurisdictions are considered to be factors which operate beyond the scope of banking supervision, the inclusion of four important forms of oversight are considered sufficient not only in ensuring that appropriate checks and balances exist, but that an effective system of corporate governance can be achieved. ${ }^{51}$ The types of oversight include:

"(1) oversight by the board of directors or supervisory board; (2) oversight by individuals not involved in the day-to-day running of the various business areas; (3) direct line supervision of different business areas; and (4) independent risk management, compliance and audit functions. In addition, it is important that key personnel are fit and proper for their jobs. "

The contribution and the role assumed by senior management in ensuring that internal control systems are effectively managed, is reflected through the Principles for the Assessment of Internal Control Systems. ${ }^{53}$ The importance of monitoring and the rectification of deficiencies within internal control systems is reflected under principles $10-12 .{ }^{54}$ Principle 10 highlights the importance of monitoring on a frequent and ongoing basis whilst principles 11 and 12 draw attention to the importance of effective collaboration and communication between highly trained competent staff, the board of directors, audit committees and senior management. ${ }^{55}$

\section{According to paragraph 84 of the BCBS Principles for Sound Liquidity Risk Management and}

Supervision of September 2008, internal coordination across business lines is vital towards ensuring that effective controls over liquidity outflows are achieved. ${ }^{56}$ In relation to examples of actions which supervisors could adopt, as means of responding to banks with liquidity risk management weaknesses or excessive liquidity risk, that which "requires actions by the bank to strengthen its management of liquidity risk through improvements in internal policies, controls or reporting to senior management and the board" is considered to have the greatest potential to address deficiencies in a bank's liquidity risk management process or liquidity position. ${ }^{57}$

As observed by the Basel Committee, ${ }^{58}$ "most banks that have experienced losses from internal control problems did not effectively monitor their internal control systems. Often the systems did not have the necessary built-in ongoing monitoring processes and the separate evaluations performed were either not adequate or were not acted upon appropriately by management." 59 Furthermore it highlights that such failures to monitor adequately commence with a "failure to

49 Basel Committee for Banking Supervision, “Enhancing Corporate Governance for Banking Organisations” 2006 at page 4

50 ibid at page 5

ibid

ibid

See particularly Principles 1-3 which relate to management oversight and the control culture; ibid at pages 2 and 3

ibid at page 4

ibid at pages 4 and 5

${ }^{56}$ Paragraph 16, as well as other sections which address and relate to internal and risk controls in particular, are considered to have the greatest importance out of all the sections within the BCBS Principles for Sound Liquidity Risk Management and Supervision of September 2008

${ }^{57}$ See paragraph 142 of BCBS Principles for Sound Liquidity Risk Management and Supervision of September 2008

58 See "Monitoring Activities and Correcting Deficiencies" Framework for Internal Controls in Banking Organisations, Basel Committee on Banking Supervision 1998 at page 30

59 See ibid at paragraph 10 
consider and react to day-to-day information provided to line management and other personnel indicating unusual activity - such as exceeded exposure limits, customer accounts in proprietary business activities or lack of current financial statements from borrowers."

In implementing the regulatory standards and monitoring tools which are highlighted by the Basel Committee in its consultative document, ${ }^{61}$ a supervisory approach which does not only incorporate the expertise of external auditors, but which is also more inclined to an on site system based approach is recommended. In supporting this view, reference is made to lessons learned from the collapse of Barings where it was noted by the Treasury Committee that "it was due to the discretionary basis of the supervisor's approach to supervision that there was limited ability to detect events at Barings." 62

The regulatory standards and monitoring tools set out in the BIS Consultative Document ${ }^{63}$ are therefore supported on the basis of their ability to facilitate a more formal approach to supervision which would reduce the scope for flexibility (scope for creative accounting practices and "window dressing" of balance sheet figures) where an on - site approach to supervision is implemented.

\section{F. On site and Off-site Supervision}

Principle 21 of the Basel Core Principles for Effective Supervision, Supervisory Reporting states that "Supervisors must have a means of collecting, reviewing and analysing prudential reports and statistical returns from banks on both a solo and a consolidated basis, and a means of independent verification of these reports, through either on-site examinations or use of external experts."

According to Vieten ${ }^{64}$ bank regulation has followed two trends, namely: supervision has become increasingly formalized and dependent on quantitative tools, and secondly, regulatory duties are being pushed down a regulatory pyramid to include external auditors and to enlist the resources of regulatees.

External auditors, even though they do not constitute by definition, part of a banking organisation, immensely impact the quality of internal controls "through their audit activities - which also includes discussions with management and recommendations for improvement to internal controls." "External auditors provide an important feedback on the effectiveness of the internal control system."

Off site supervision is synonymous with monitoring and involves the regulator's use of external auditors' expertise. It also involves the receipt and analysis of financial statements and statistical returns submitted to the supervisors. Off site monitoring often has the benefits of being able to identify potential problems, particularly during intervals between on- site inspections, thereby providing early detection and acting as trigger for corrective action before problems become more

\footnotetext{
60 See ibid at paragraph 11

61 See Consultative Document ,International Framework For Liquidity Risk Measurement, Standards and Monitoring December 2009

62 Treasury Committee Barings Bank and International Regulation Report No 1 (1996) at page xiv

63 Consultative Document ,International Framework For Liquidity Risk Measurement, Standards and Monitoring December 2009

64 See HR Vieten, „Banking Regulation in Britain and Germany Compared: Capital Ratios, External Audit and Internal Controls“" (1997) at page 18

65 Framework for Internal Control Systems in Banking Organisations, page 25 Basel Committee on Banking Supervision 1998

66 ibid
} 
serious. ${ }^{67}$

On site work is usually done by the examination staff of the bank supervisory agency or commissioned by supervisors but may be undertaken by external auditors. Furthermore, it is contended that on-site examinations are frequently implemented by banking supervisory authorities which posses the legal basis or other arrangements to direct the scope of the work carried out by external auditors. $^{68}$

Ongoing monitoring is contrasted with separate evaluations. It is highlighted that whilst ongoing monitoring activities not only provide the advantage of "quickly detecting and correcting deficiencies in the system", but are also most effective "when the system of internal control is integrated into the operating environment and produces regular reports for review," that separate evaluations usually detect problems "only after the fact." ${ }^{69}$ However separate evaluations also offer the advantage of providing an organisation with "fresh and comprehensive" insight into the effectiveness of monitoring activities - such activities being undertaken by staff from different departments which include the business function, financial control and internal audit. ${ }^{70}$

\section{G. Monitoring Compliance and Enforcement}

\section{Principles Based Regulation}

A discretionary based approach to regulation, whilst encouraging greater possibilities for regulatory capture, appears to be more congruent with principles based regulation. However it is possible to implement a system of regulation which combines increased formalised procedures and/or detailed rules - whilst giving due consideration to the substance of transactions.

"Principles provide the framework in which firms can organize their own processes to achieve the outcomes the regulator seeks - the regulator in turn, depends on firms to adopt an attitude to the regulatory regime (which is one which aims to go beyond minimal compliance with rules)."${ }^{, 71}$

Principles based regulation is not only advantageous because it allows management of a bank or firm to take into consideration the substance of transactions, but because "principles impose outcomes to be achieved - not detailed processes for achieving them." meta regulation, principles based regulation facilitates a system whereby principles "communicate regulatory objectives and promote behaviour which will achieve those objectives."

Principles based regulation, thus, would not only reduce the scope for "creative compliance" - since the substance of transactions should be considered by management, but also has the benefit of providing a more flexible and responsive approach to regulation as the subsequent section will seek to demonstrate.

${ }_{67}$ See „The Relationship between Banking Supervisors and Banks' External Auditors January 2002 paragraph 40 page $11<$ http://www.bis.org/publ/bcbs87.pdf?noframes=1>

68 See Framework for Internal Control Systems in Banking Organisations, Basel Committee for Banking Supervision 1998 at page 23

69 ibid at page 20.

70 ibid

71 See J Black, „Forms and Paradoxes of Principles Based Regulation“ LSE Law, Society and Economy Working Papers 13/2008 (2008) at page 9 http://www.lse.ac.uk/collections/law/wps/wps.htm and

http://www.ssrn.com/abstarct $=1267722$

72 ibid

73 ibid at page 16 
Principles based regulation is considered to comprise of 3 elements, namely: ${ }^{74}$

i) A particular type of rule

ii) A focus on outcomes and

iii) A focus on senior management responsibility in ensuring these outcomes are achieved

Furthermore, three forms of principles based regulation, namely: "formal principles based regulation; substantive principles based regulation and full principles based regulation", have been suggested. ${ }^{75}$ For the purposes of this paper, focus will be restricted to substantive principles based regulation.

- Five classes of regulatory practices which could characterise substantive principles based regulation include: ${ }^{76}$ "The particular mode of interpretation- that is, the approach taken in the interpretative process; particular enforcement style; an orientation to outcomes; a relocation of responsibilities for working out the practical application of the provisions; and an explicit and developed reliance on management based regulation."

The effectiveness of rules and regulation is dependent, not only on the monitoring processes and tools used in such processes, but also the effectiveness of the enforcement of those rules. For this reason, focus will be dedicated to the second characteristic of substantive principles based regulation- which is indeed a "critical" and defining feature of principles based regulation.

According to Black, the adoption of the "responsive" enforcement approach is justified on the basis that "neither negotiative approaches nor deterrence based approaches are effective on their own and that instead, regulators should implement a mixture of both, that is, first negotiate, then if the firm still does not deliver substantive compliance, regulators should gradually move up the enforcement pyramid, applying sanctions of increasing severity until it does." ${ }^{\prime 77}$ She adds weight to Baldwin's argument $^{78}$ by stating that "those who know what they are meant to be doing and are generally inclined to do it ("the well intentioned and well informed"), are best dealt with using a negotiating strategy - which is easier to do using principles. In contrast, those who do not know what they are meant to be doing and even if they did, would not be inclined to do it ("the ill intentioned and ill informed"), are best dealt with using a strategy that escalates rapidly up the enforcement pyramid." 79

This "responsive" approach, it is further argued, "is not contingent on any particular rule design and can operate in systems of i) highly detailed rules, ii) where the rules are mainly principles, iii) where there is a combination of both."

\footnotetext{
74 See J Black, „Forms and Paradoxes of Principles Based Regulation“ LSE Law, Society and Economy Working Papers 13/2008 (2008) at page 12

75 ibid

76 ibid at page 17

77 See also I Ayres and J Braithwaite, Responsive Regulation (1992) Oxford University Press

78 See R Baldwin, Rules and Government (1995) Oxford : Clarendon Press

79 J Black, „Forms and Paradoxes of Principles Based Regulation“ LSE Law, Society and Economy Working Papers $13 / 2008$ (2008) at page 19; She argues that "in a regime with a tough, punitive approach in which every infraction is met with a sanction, principles based regulation (PBR) would not survive - this being the case, because there is greater risk that firms will make the wrong assessment ie one with which the regulator does not agree." Under principles based regulation, she argues further, "firms are required to think through the application of the provisions to particular situations to a far greater degree than they are with respect to a detailed rule - hence the higher probability that firms would make the wrong assessment." See ibid at page 18

80 J Black, „Forms and Paradoxes of Principles Based Regulation“ LSE Law, Society and Economy Working Papers $13 / 2008$ (2008) at page 19; It is further argued that "Different rule types make it easier for regulatory officials to
} 
Having considered the forms, attributes and benefits of principles based regulation, the weaknesses inherent in this type of regulation are worth mentioning. Firstly, in relation to the all important aim of ensuring accountability - which should be fostered if adequate monitoring procedures are observed and carried out by the responsible levels of authority. Principles based regulation could serve as a hindrance towards ensuring accountability. In this respect, reference will be made to the seven paradoxes of principles based regulation - which are as follows: ${ }^{81}$

- “i) The interpretative paradox : Different interpretations attributed to principles could result in imprecise and general terms being accorded very specific interpretations - even though principles are supposed to offer flexibility (where these are characterised by imprecise terms).

- ii) The communicative paradox: Principles, whilst facilitating communication, could also hinder such communication. The paradox is attributed to the distinction between legal use of language and its ordinary use.

- iii) The compliance paradox: Principles provide scope for flexibility in compliance - however this could result in conservative and/or uniform behaviour by regulated firms.

- iv) The supervisory and enforcement paradox: Principles require enforcement to provide them with credibility - however over-enforcement could result in their demise.

- v) The internal management paradox: Principles based regulation has the potential to offer required flexibility for internal control systems to develop - and also the potential to overload them.

- vi) Ethical paradox

- vii) Trust paradox

A detailed consideration of the above mentioned paradoxes highlights the importance of having a clear understanding of the form of principles based regulation which is applicable to a particular bank or business. As highlighted under the substantive principles based regulation, "those who know what they are meant to be doing and are generally inclined to do it ( the well intentioned and well informed), are best dealt with using a negotiating strategy." Hence a more draconian mode of enforcement, that is tougher sanctions, would not be best suited in facilitating compliance by such groups - such sanctions being better reserved for the "ill informed and ill intentioned." Furthermore, a tough punitive regime is one in which principles are unlikely to survive - even though detailed rules could still be implemented under principles based regulation. ${ }^{82}$

Hence the desired level of compliance required within a firm is best achieved having regard to the organisational structure which exists within an organisation - and to whether (as a result of a such determination), that organisation could be considered a suitable candidate for the application of principles based regulation. Clear delegation and segregation of duties within an organisation would not only promote accountability, but would also facilitate a system where principles could be applied and also facilitate monitoring procedures. Consequently, monitoring would also facilitate accountability - since frequent reviews and discussions between management and appropriate personnel should increase an understanding of the activities carried out by particular divisions within the organisation.

deal with certain types of regulated firms."

81 See ibid at pages $25-35$

82 Refer to Formal Principles Based Regulation; ibid at page 12 
Monitoring fosters transparency, which in turn fosters accountability. Monitoring of key risks, as well as periodic evaluations by the business lines and internal audit constitute a vital element of corporate governance - hence the overall effectiveness of a bank's internal controls should be monitored on an ongoing and frequent ${ }^{83}$ basis. $^{84}$

Since it is possible for detailed rules to operate under principles based regulation - and since detailed rules constitute a vital element in ensuring that clear delegation and segregation of responsibilities exist within an organisation, it could be said that the level of accountability derived under principles based regulation is dependent on the form of principles based regulation. Under the formal principles based regulation, the level of accountability derived is likely to be greater than that derived under full principles based regulation. As highlighted within the relevant sections of this paper, an approach which combines negotiating and punitive strategies is always considered best - owing to the level of flexibility offered by such an approach. However the organisational structure, culture and several other factors require consideration before substantive principles based regulation is judged to be the optimal approach.

In accordance with Principle 13 of the Principles for the Assessment of Internal Control Systems, "supervisors should require that all banks, regardless of size, have an effective system of internal controls that is consistent with the nature, complexity, and risk inherent in their on- and- off balance sheet activities and that corresponds to the bank's environment and conditions." Furthermore, "in those instances where supervisors determine that a bank's internal control system is not adequate or effective for that bank's specific risk profile, they should take appropriate action." In accordance with Core Principle 17 of the Basel Core Principles for Effective Bank Supervision, Internal controls and audit, specific attention should given to ensure the existence of: i )"clear arrangements for delegating authority and responsibility; (ii)separation of the functions that involve committing the bank, paying away its funds, and accounting for its assets and liabilities."

Where clear delegation of authority, segregation of responsibilities are not in place, the most appropriate and obvious action might be to initiate a more deterrence based approach - rather than a negotiative based approach. However, reference must be made to factors highlighted under the first paragraph of this conclusive section.

Increased formalisation under principles based regulation would still allow for a consideration of the substance of transactions - whilst allowing for flexibility in terms of its application. With regards to its application, this implies its suitability as the appropriate mode of regulation - based on the level of accountability it could provide an organisation with and whether an organisation, because of its structure and culture, should consider applying it at all.

83 "The frequency of monitoring different activities of a bank should be determined by considering the risks involved and the frequency and nature of changes occurring in the operating environment." See Framework for Internal Control Systems in Banking Organisations at page 20 http://www.bis.org/publ/bcbs40.pdf

84 See also Principle 10 of the Principles for the Assessment of Internal Control Systems; Framework for Internal Control Systems in Banking Organisations at page 20 http://www.bis.org/publ/bcbs40.pdf. "Monitoring the effectiveness of internal controls could be undertaken by personnel from several different areas, including the business function itself, financial control and internal audit. For that reason, it is important that senior management clarify which personnel are responsible for which monitoring functions." Further, "monitoring should constitute part of the daily activities of the bank - whilst including separate periodic evaluations of the overall internal control process. ";ibid 


\section{REFERENCES}

Accompanying Document to the Proposal for a Directive of the European Parliament and of the Council amending Capital Requirements Directive on trading book, securitisation issues and remuneration policies.

$<\underline{\text { http://ec.europa.eu/internal_market/bank/docs/regcapital/com2009/impact_assesment_en.pdf }>}$

Ayres I and Braithwaite J, Responsive Regulation (1992) Oxford University Press

Baldwin R, Rules and Government (1995) Oxford : Clarendon Press

Basel Committee on Banking Supervision, Consultative Document „International Framework for Liquidity Risk Measurement, Standards and Monitoring, December 2009 Bank for International Settlements Publications

Basel Committee on Banking Supervision, Principles for Sound Liquidity Risk Management and Supervision Sept 2008

Basel Committee on Banking Supervision, "Enhancing Corporate Governance for Banking Organisations" February 2006

Basel Committee on Banking Supervision, Monitoring Activities and Correcting Deficiencies" Framework for Internal Controls in Banking Organisations, 1998

Beattie V, Fearnley S, and Brandt R Behind Closed Doors: What Company Audit is Really About (ICAEW) 2001

Black J, „Forms and Paradoxes of Principles Based Regulation“ LSE Law, Society and Economy Working Papers 13/2008 (2008) http://www.lse.ac.uk/collections/law/wps/wps.htm

Financial Stability Forum, Report of the Financial Stability Forum on Addressing Pro cyclicality in the Financial System: Measuring and Funding Liquidity Risk" http://www.financialstabilityboard.org/publications/r_ 0904a.pdf

Framework for Internal Control Systems in Banking Organisations”, Basel Committee for Banking Supervision 1998

Hadjiemmanuil C, Banking Regulation and the Bank of England (1995) Lloyds of London Press

House of Commons Select Committee on Treasury, Minutes of Evidence submitted by the Institute of Chartered Accountants in England and Wales as part of its inquiry into the arrangements for financial regulation of public limited companies at page 17

Keasy K and Wright M, 'Issues in Corporate Accountability and Governance: An Editorial' Accounting and Business Research, 23 (91A) at page 291

Mogg JF, ,The Bank of England and the Development of Internal Control Systems' in R Kinsella (ed) Internal Controls in Banking (1995) Oak Tree Press Dublin 
The Relationship between Banking Supervisors and Banks' External Auditors January 2002 paragraph 40 page $11<\mathrm{http}$ //www.bis.org/publ/bcbs87.pdf?noframes=1

Treasury Committee, Barings Bank and International Regulation Report No 11996

Vieten HR, „Banking Regulation in Britain and Germany Compared: Capital Ratios, External Audit and Internal Controls“"(1997) 